\title{
AMPLIAÇÃO DO ENSINO FUNDAMENTAL DE NOVE ANOS NAS CONSTITUIÇÕES E LEIS DE DIRETRIZES E BASES DA EDUCAÇÃO BRASILEIRA.
}

\author{
Leonardo de Angelo Orlandi, José Milton de Lima \\ Universidade Estadual Paulista - UNESP, Grupo de Pesquisa Cultura Corporal: Saberes e Fazeres, Programa de Pós- \\ Graduação em Educação, Presidente Prudente, SP. E-mail: leo angeloorlandi@hotmail.com
}

\begin{abstract}
RESUMO
Esta pesquisa tem como temática a ampliação do ensino fundamental nas consitutições e leis de diretrizes e bases da educação brasileira e apresenta como objeto de estudo os principais documentos oficiais relacionados a educação brasileira. O objetivo central: situar o panorama geral de como se estruturaram essas transformações na trajetória educacional brasileira realizando uma revisão ao histórico relativo à questão da obrigatoriedade escolar no Brasil, analisando fatos e dispositivos sociais e jurídicos que articulam-se a pretensa realidade de expansão do ensino obrigatório para nove anos. A investigação de natureza qualitativa adotou a metodologia análise documental. Para tal fim, a investigação analisou as Constituições Brasileiras (1824, 1891, 1934, 1937, 1946, 1967, 1988) e as Leis de Diretrizes e Bases (4.024/61; 5.540/68; 5.692/71 e 9394/96). Os resultados demonstraram que a ampliação da escolaridade no Brasil através das legislações, foi envolto de polêmicas, contradições e conflitos que envolviam forças e correlação de desejos.
\end{abstract}

Palavras-chave: Ensino Fundamental; Infância; Aprendizagem; Criança; Educação.

\section{EXPANSION OF BASIC EDUCATION OF NINE YEARS IN THE CONSTITUTIONS AND LAWS OF GUIDELINES AND BASES OF BRAZILIAN EDUCATION.}

\begin{abstract}
This research has as its theme the expansion of primary education in the consitutições of laws and guidelines and bases of Brazilian education and presents as object of study the main official documents related to Brazilian education. The central objective: situate the overview of how structured these transformations in the Brazilian educational trajectory conducting a historical review on the issue of compulsory school in Brazil, analyzing facts and social and legal devices that articulates the so-called reality of expansion of compulsory education to nine years. Research of qualitative nature adopted the methodology document analysis. To this end, the research analyzed the Brazilian Constitutions $(1824,1891,1934,1937,1946,1967,1988)$ and the laws of guidelines and Bases (4.02461; 5.54068; 5.69271 and 939496). The results showed that the expansion of schooling in Brazil through the legislation, was shrouded in controversy, contradictions and conflicts involving strength and correlation of desires.
\end{abstract}

Keywords: Elementary School; Childhood; Learning; Child; Education. 


\section{INTRODUÇÃO E OBJETIVO}

A questão da regulamentação do Ensino Fundamental de Nove anos configura uma medida extremamente atual e controvérsia. A partir da aprovação da Lei no 11.274/06, o Ensino Fundamental passou a ter a duração de nove anos, com a inclusão obrigatória das crianças de seis anos nesse estágio da escolaridade.

Essa determinação, que consolidou a proposição de expansão desse nível de ensino contida na Lei de Diretrizes e Bases da Educação Nacional, Lei no 9.394/96, e no Plano Nacional de Educação - PNE, Lei no 10.172/01, incorporou ao sistema educacional brasileiro um número maior de crianças, especialmente aquelas oriundas dos setores populares, uma vez que as de classes média e alta já se encontravam, majoritariamente, incorporadas ao sistema.

Nesse sentido, a experiência educacional brasileira, que possuía o tempo mínimo obrigatório de escolaridade de 8 anos que preponderava em território nacional desde 1971, a partir da vigência da Lei no 5.692/71 e perdurado com a Lei no 9.394/96 sofreu alterações na sua estrutura e funcionamento. Tal movimento de política de ampliação dos anos de escolaridade do Ensino Fundamental nos remete às transformações históricas acerca da educação obrigatória, tanto no Brasil quanto em outros países.

Nesse contexto, a fim de situar o panorama geral de como se estruturaram essas transformações na trajetória educacional brasileira, faz-se uma revisita ao histórico relativo à questão da obrigatoriedade escolar no Brasil, analisando fatos e dispositivos sociais e jurídicos que se articulam a pretensa realidade de expansão do ensino obrigatório para nove anos. Pretendeuse, portanto, nesta investigação, esboçar um quadro geral do lugar do Congresso Nacional na política e educação brasileira, destacando os principais elementos que constituem a ação desempenhada pelo Congresso Nacional em relação a ampliação da obrigatoriedade do Ensino Fundamental.

Justificou-se tal esforço por acreditar que a referência a esses antecedentes facilitará a compreensão do significado da ampliação do ensino obrigatório na experiência educacional brasileira, uma vez que as Constituições Brasileiras (1824, 1891, 1934, 1937, 1946, 1967, 1988) e as Leis de Diretrizes e Bases (4.024/61; 5.540/68; 5.692/71 e 9394/96) têm sistematicamente “[...] consagrado a distinção, harmonia e independência entre os poderes fundamentais que alicerçam a organização da vida política: o Executivo, o Judiciário e o Legislativo" (SAVIANI, 1988, p. 27).

Para tanto, organizamos um breve histórico, abarcados em autores como Saviani (1988) e Vieira (2007), da educação obrigatória e gratuita nas Constituições Brasileiras, nas Leis de Diretrizes e Bases da Educação Nacional e suas reformas pertinentes à política de ampliação do 
ensino básico, até chegar ao Plano Nacional de Educação vigente e, posteriormente, refletir sobre as leis resoluções e pareceres da implementação do Ensino Fundamental de nove anos.

\section{METODOLOGIA}

A presente pesquisa, visando a elucidar os objetivos propostos, assumiu a metodologia qualitativa, visto que não teve como objetivo enumerar e/ou medir dados coletados, conforme no método quantitativo e sim "traduzir e expressar o sentido dos fenômenos do mundo social; tratase de reduzir a distância entre indicador e indicado, entre teoria e dados, entre contexto e ação" (NEVES, 1996, p. 01). A adoção do paradigma qualitativo foi importante para o nosso estudo, pois seu objetivo não foi fazer generalizações do tipo estatístico, mas sim uma análise interpretativa e crítica do material coletado.

Compartilhando dessas questões, para que os dados pudessem ser devidamente analisados e interpretados, transformando-se em conhecimentos relevantes para a área, selecionamos a análise documental para subsidiar melhor a descrição das características dos documentos oficiais consultados, do contexto e do fenômeno na sua relação com suas distintas variáveis. A propósito da pesquisa documental, a sua importância principal “[...] em pesquisa educacional, está no desenvolvimento do currículo, no qual o pesquisador pode fazer um levantamento do que está acontecendo ou do que aconteceu, pelo que foi registrado em materiais escritos ou impressos" (RUMMEL, 1972, p. 152). Nesse sentido, no intuito de identificar informações factuais que nos auxiliassem na compreensão do objeto de estudo, a análise contemplou os seguintes documentos: Constituições e Leis de Diretrizes e Bases até a data de 1988. Tal procedimento visou contribuir na explicitação do problema da pesquisa e ao mesmo tempo, permitir análises, a partir do suporte teórico, que aprofundaram a compreensão e interpretação acerca da ampliação do Ensino Fundamental.

\section{RESULTADOS E DISCUSSÕES}

$\mathrm{Na}$ contemporaneidade a educação tem sido pauta de muitas discussões, reflexões e análises no que diz respeito à implementação e efetivação das políticas públicas em relação ao acesso a educação obrigatória.

Nesse sentido, no que diz respeito à educação, o Estado brasileiro assumiu pela primeira vez o compromisso com esse direito na Constituição de 1934 na qual determinava que "a educação é direito de todos e deve ser ministrada pela família e pelos poderes públicos". Entretanto, Vieira (2007) afirma que apesar da pequena preocupação suscitada pela matéria 
educativa naquele momento político, é possível encontrar na Constituição de 1824 indícios de cunho educacional.

Assim, apesar de o Brasil ter sido um dos primeiros países a inscrever em sua legislação a gratuidade da educação a todos os cidadãos, esta não se efetivou na realidade social no âmbito da obrigatoriedade do ensino. Portanto, não é estranho que, mesmo no nível das expectativas, a República silencie acerca da educação do qual o Império se pronuncia, visto que nesse contexto, o texto constitucional passa ao largo da matéria educacional.

Por conseguinte, a primeira Constituição republicana, promulgada em 24 de fevereiro de 1891 é resultado da construção de uma forma de governo marcada por contradições. Na visão de Vieira (2007) a Carta Magna Republicana de 1891 apresenta maior número de dispositivos sobre educação que o texto de 1824 , mas ainda não chega a ser um salto qualitativo em relação à obrigatoriedade do ensino.

No tocante, em meio ao veemente debate entre duas correntes de pensamento educacional da época - o tradicionalismo católico e o liberalismo - foi promulgada a segunda Constituição da República, de 16 de julho, de 1934. Atendendo ao movimento liberal, a Constituição de 1934 é a primeira a dedicar espaço significativo à educação ao tratar na seção II das atribuições do Poder Legislativo, distinguindo as competências privativas sujeitas a sanção presidencial, em número de doze, e as competências exclusivas, que atingem o total de onze (cap. II, arts. 148 a 158).

Nesse sentido, a Constituição de 1934 é a primeira que avança consideravelmente em relação à obrigatoriedade do ensino brasileiro. Todavia, devido ao resultado das discussões entre liberais, católicos e integralistas o ensino que se expandia, era controlado pelas elites, o que fez o estado agir mais pelas pressões do momento e de maneira improvisada do que buscando delinear uma política nacional de educação com o objetivo de tornar universal e gratuita a escola elementar.

Na sequência, a Carta Constitucional de 10 de novembro de 1937, outorgada por Getúlio Vargas não define explicitamente as atribuições do Congresso Nacional. Na contramão da redação liberal de 1934, a Constituição do Estado Novo é evidentemente inspirada nas constituições de regimes fascistas europeus. Apesar de ampliar no seu Artigo 15, seção IX a competência da União para "fixar as bases e determinar os quadros da educação nacional, traçando as diretrizes a que deve obedecer à formação física, intelectual e moral da infância e da juventude", a Carta de 1937 exclui da redação constitucional o artigo que garantia a "educação como um direito de todos" presente na Carta de 1934 e atribui aos pais a "educação de sua prole". Assim, em relação à 
ampliação da obrigatoriedade de ensino que ficava marcada como inovadora na Carta de 1934, regride na Constituição de 1937, marcando uma nova postura de paralisação ou enfraquecimento das conquistas já alcançadas para a educação.

Por conseguinte, a Constituição promulgada a 18 de setembro de 1946 retoma a tradição republicana e reestabelece também o estado de direito e a autonomia federativa definindo nove atribuições do Congresso Nacional a sanção presidencial e dez de sua competência exclusiva, conforme estipulado nos artigos 65 e 66 da seção IV. Vieira (2007) explana que a redação de 1946 faz ressurgir o tema da educação como direito de todos. No entanto, tal temática não estabelece vínculo direto entre esse direito e o dever do Estado em um mesmo artigo, como ocorrera no texto de 1934.

Diante dessa realidade e fruto de longos e intensos debates, iniciados em 1947 com o projeto de lei encaminhado à Câmara Federal e encerrados com sua promulgação somente em 20 de dezembro de 1961, nasce a primeira Lei de Diretrizes e Bases da Educação Nacional, a Lei 4.024/61. Essa longa discussão culminou na regressão e na não contemplação da intenção legal da Constituição de 1946, que previa a obrigatoriedade e gratuidade do ensino primário.

Nesse contexto, a lei aprovada em 1961 contemplou a estratégia de conciliação entre os que defendiam a escola pública laica, obrigatória e gratuita, e os conservadores, que defendiam os interesses da iniciativa privada, colocando para a família a responsabilidade de escolha do gênero da educação. Posteriormente, a Lei de Diretrizes e Bases no 4.024/61 passou por duas reformas substanciais: no ano de 1968, com a Lei no 5.540 e no ano de 1971 , com a Lei no 5.692 . No entanto, entre essas duas reformas, o Brasil volta a mergulhar numa fase marcada pelo autoritarismo. Com o golpe militar de 1964, ocorreu o fechamento da ordem política por um período superior àquele que, de início, parecia anunciar-se. Sob a égide da ditadura, é concebido um novo marco legal para o país, a começar pela Carta Magna de 24 de janeiro de 1967, assim como a emenda Constitucional no 1 de 17 de outubro de 1969, baixadas ambas já na vigência do regime militar implatado com o golpe de estado de 1964.

Nesse cenário, a Carta Constitucional de 1967 garante que a educação é um "direito de todos" e acrescenta "o dever do estado" (art. 176). Outro aspecto importante é a definição da faixa etária destinada ao ensino obrigatório: Art. 168, § 3으, inciso II - "o ensino dos sete aos quatorze anos é obrigatório para todos e gratutito nos estabelecimentos primários oficiais".

De acordo com Vieira (2007), é posterior à Constituição de 1967 o encaminhamento das principais propostas de reforma educacional do período militar. Todavia, é preciso fazer referência a elas, pelo fato de marcarem enfaticamente o cenário dos anos subsequentes. Para a autora 
(2007), primeiro é concebida a reforma do ensino superior (Lei no 5.540/68). No tocante, a reforma da educação básica, que fixa as diretrizes e bases para o ensino de 1으 e 2ㅇ graus (Lei no 5.692/71). Essas legislações mudam substancialmente o ensino obrigatório no país e proporcionam uma universalização da educação básica. Pelo que se pode observar, esta lei trouxe avanços significativos quanto à ampliação da educação obrigatória, aumentando-a de quatro para oito anos.

No tocante, a Carta Constitucional de 1988 é a mais extensa de todas em matéria de educação, sendo detalhada em dez artigos específicos (arts. 205 a 214) e figurando em quatro outros dispositivos (arts. 22, XXIV, 23, V, 30, VI, e arts. 60 e 61 do Ato das Disposições Constitucionais Transitórias - ADCT). Pela primeira vez, a Constituição prevê "gratuidade do ensino público em estabelecimentos oficiais de ensino" (Artigo 206, inciso IV) e não só no Ensino Fundamental, mas em qualquer nível ou etapa de ensino. Quanto à obrigatoriedade, restringe-se ainda ao ensino fundamental (artigo 208, inciso I), no entanto, reza o acesso à escolaridade obrigatória como direito público subjetivo (Artigo 208, § 1ํ).

Como resultado dessa proposição, fruto de grandes embates e discussões é formulada a Lei de Diretrizes e Bases da Educação Nacional no 9.394/96 em 20 de dezembro de 1996. Tal legislação decorreu da necessidade de se reorganizar a educação nacional em função da nova Constituição de 1988, que definiu os pilares para uma educação com vertente processual de alargamento da cidadania e dos direitos humanos. Desse modo, a Lei 9.394/96 tem seus presupostos inspirados não somente na nova Constituição, mas, sobretudo no espírito/pensamento que a regeu.

\section{CONSIDERAÇÕES FINAIS}

Realizada a análise do objeto específico dessa investigação, qual seja, o significado político do papel desempenhado pelo Congresso Nacional na elaboração das Constituições e, consequentemente, as Leis de Diretrizes e Bases da Educação Nacional e os Planos Nacionais de Educação em relação a ampliação da escolaridade no Brasil, podemos inferir algumas suposições acerca desse histórico.

Nesse sentido, as Cartas Constitucionais e as Leis de Diretrizes e Bases constituem parte integrante do processo de elaboração e problematização das legislações que tangem a obrigatoriedade do ensino e sua progressiva expansão. Assim, através desse breve histórico, procuramos deslindar o sentido histórico, social e político das referidas legislações. 
Perante a esse contexto, as legislações mencionadas, por desempenharem uma contribuição singular do Congresso Nacional aos projetos oriundos do Poder Executivo, integram o mecanismo de compreensão da função do Congresso Nacional na elaboração e efetivação das legislações educacionais. Tal especificidade é de extrema importância para a compreensão do percurso histórico no qual a educação brasileira foi pautada durante seu processo de ampliação da obrigatoriedade do ensino básico. Desse modo, o entendimento da efetivação das Constituições e das respectivas Leis de Diretrizes e Bases na legislação abre uma perspectiva interessante para os estudos sobre o Ensino Fundamental de nove anos. Isto porque, como tentamos demonstrar, torna-se possível articular o contexto de criação das leis e as propostas realmente efetivadas durante os períodos destacados.

Nesse contexto, a análise das constituições indicaram que o caminho legislativo da política educacional brasileira da ampliação da escolaridade obrigatória no viés democrático, é uma medida positiva, pois prevê uma extensão dos anos de escolaridade para as crianças brasileiras. Entretanto, é preciso ressaltar que, no cunho de ampliação da escolaridade no Brasil através das legislações, este processo foi envolto em polêmicas, contradições e conflitos que envolviam forças e correlação de desejos.

Diante dessas reflexões, podemos afirmar que o estudo das constituições é tema relevante para a problematização sobre a política educacional de implementação do ensino no Brasil por duas razões. A primeira está vinculada a questão da presença ou não da educação nas Constituições Brasileiras, visto que evidencia seu menor ou maior grau de importância ao longo da história. Nas primeiras constituições (1824 e 1891) as referências são mínimas, ilustrando sua pequena relevância para a sociedade da época. Com o aumento da demanda por acesso à escola, a presença de artigos relacionados com o tema cresce substancialmente nas constituições posteriores (1934, 1937, 1946, 1967 e 1988).

A segunda dimensão ressalta que as articulações de interesses de grupos majoritários influenciam de maneira significativa na implementação e mudança do sistema de ensino no decorrer da história das legislações federais. Percebeu-se claramente em diversos textos a influência de grupos na elaboração das legislações como no caso de 1934, do qual as ideias liberais aparecem no texto constitucional e, em 1937 o movimento é no sentido inverso. No entanto, se alguns temas perpassam o conjunto das constituições, outros são exclusivos de determinados momentos históricos, expressando suas marcas. É somente considerando a especificidade da educação que os legisladores conseguirão realmente articular a criação de dispositivos 
educacionais efetivos na legislações brasileiras com uma formação humanizadora, uma vez que tais leis são frutos das necessidades sociais de uma determinada população.

\section{REFERÊNCIAS}

. Constituições Brasileiras: 1824. vol. I. Brasília: Senado Federal e Ministério da Ciência e Tecnologia, Centro de Estudos Estratégicos, 2001a.

. Constituições Brasileiras: 1891. vol. II. Brasília: Senado Federal e Ministério da Ciência e Tecnologia, Centro de Estudos Estratégicos, 2001b.

. Constituição Federal de 1934. Brasília. Disponível em: www.planalto.gov.br. Acesso em: 3 mar. 2012.

. Constituição dos Estados Unidos do Brasil. 1937. Brasília. Disponível em:

www. planalto.gov.br. Acesso em: 3 mar. 2012.

. Constituição Federal dos Estados Unidos do Brasil de 1946. Brasília. Disponível em: www.planalto.gov.br. Acesso em: 3 mar. 2012.

. Constituição da República Federativa do Brasil de 1967. Brasília. Disponível em: www.planalto.gov.br. Acesso em: 3 mar. 2012.

. Constituição da República Federativa do Brasil de 1988. Brasília. Disponível em: www.planalto.gov.br. Acesso em: 3 mar. 2012.

. Lei no 5.540/1968. Fixa normas de organização e funcionamento do ensino superior e sua articulação com a escola média, e dá outras providências.Brasília. Disponível em: www.planalto.gov.br. Acesso em: 13 nov. 2011.

. Lei no 9.394/1996. Estabelece as Diretrizes e Bases da Educação Nacional. Brasília. Disponível em: www.planalto.gov.br. Acesso em: 13 nov. 2010.

. Lei no. 11.274/2006. Altera a redação dos artigos 29, 30, 32 e 87 da Lei no. 9.394, de 20 de dezembro de 1996. Diário Oficial [da] República Federativa do Brasil, Brasília, DF, 2006. Disponível em: <http://www.planalto.gov.br. Acesso em: 05 ago. 2010.

NEVES, J. L. Pesquisa qualitativa: características, usos e possibilidades. Cadernos de Pesquisas em Administração, v. 1, n.3, 2o sem., 1996.

RUMMEL, J. F. Introdução aos procedimentos de pesquisa em educação. Porto Alegre, Editora Globo, 1972.

SAVIANI, D. Escola e democracia: teorias da educação, curvatura da vara, onze teses sobre educação e política. Campinas: Autores Associados, 1988.

VIEIRA, S. L. A educação nas constituições brasileiras: texto e contexto. Rev. bras. Est. pedag., Brasília, v. 88, n. 219, p. 291-309, maio/ago. 2007. 